\title{
A Pedagogical Perspective: An Exploration into Feedback and Group Work
}

\section{Ryan Thomas Williams}

Ph.D. Student, School of Social Sciences, Humanities and Law, Teesside University, Middlesbrough, Tees Valley, TS1 3BX, UNITED KINGDOM

*Corresponding Contact:

Email: ryan.williams@tees.ac.uk

Manuscript Received: 05 Feb 2021 - Revised: 29 Mar $2021 \quad$ - Accepted: 14 April 2021

\begin{abstract}
There is a large body of education literature that discusses group work and feedback in a pedagogical sense. This is predominantly a consequence of a high percent of the literature being substantially social constructivist driven. However, there is still a significant need for research in this area due to a) the ever changing 21st century and b) the amount of unanswered questions for teachers and practitioners, such as: How does an educator assign group tasks that encourage involvement, independence, a fair share of labour and in line with the curriculum? This short paper explored feedback and group work in a secondary setting using the author's teaching experience as reference points throughout. More specifically, the paper highlighted strategies such as Kagan have become very popular in mainstream education over the last 5 years. Upon evaluating Kagan strategies, it was discovered that there was a need for pre-teaching of the strategies for pupils.
\end{abstract}

Keywords: Pedagogy, Group Work, Exploration Feedback, Deeper Exploration

This article is is licensed under a Creative Commons Attribution-NonCommercial 4.0 International License. Attribution-NonCommercial (CC BY-NC) license lets others remix, tweak, and build upon work non-commercially, and although the new works must also acknowledge \& be non-commercial.

\section{INTRODUCTION}

Pedagogy constructs a method composed of both teaching practice and academic concepts. The last few decades has seen the definition of pedagogy vary a significant amount. In the 1980s pedagogy was defined as an abstract utopia line that does not underpin daily workings of a teacher (see Ellsworth, 1989a; 1989b). Modern day researchers and academics view pedagogy as a critical education movement that in principle helps teachers develop their practice (see Giroux, 2017). Despite a contrast in definitions, a reoccurring theme from studies throughout the last few decades is that there is an invisibility of pedagogy in centralised education (see Lusted, 1986; Ladwig et al., 2007; Giroux and Shannon, 2013).

It is widely accepted that when pedagogical strategies are carefully used, the outcomes produce efficient, knowledgeable graduates and teachers (see Brown et al., 2009). 
Favoured strategies include differentiation, questioning, feedback and group work. There are strands of techniques within these strategies and with a combination of solid evidence, educators are able to answer questions such as: Will boys respond better to certain types of feedback than girls? Educational psychologists can now confirm that girls set higher standards for themselves, thus evaluate their performance more critically than boys (see Feingold, 1993; Costa et al., 2001). A further study from Pomerantz et al., (2002) believe that this has little to do with social constructs and more to do with the difference in motivational factors. For example, girls are more concerned with pleasing adults such as teachers and parents whereas boys are more motivated by extrinsic, material rewards. It is important to note that these differences are "significantly more applicable to pupils up to the age of 9 " Costa et al. (2001).

In an environment of constrained resources and quality assurance efforts, institutions across the U.K. are now having to develop creative ways to implement their pedagogy learnings into $21^{\text {st }}$ century teaching. Over the last 15 years, American institutions have become better at preparing their students for employment by implementing group work and collaborative learning strategies (see Myers et al., 2016). Collaborative learning was deeply established in Vygotsky's 1920's Zone of Proximal Development (ZPD), and it is thought this is the origin of pedagogy of collaborative learning. Although derived from a communist education system in the old Soviet Union, westerners (including U.K. and U.S.A.) have recently acquired group work and the research in their education systems (see Murphy et al., 2015; O'Sullivan and Seabra, 2016).

\section{Group Work and Feedback Exploration}

With international recognition of group work and contemporary research focused on feedback from the teacher including the use of digital technologies, both will be explored further throughout the essay. It is now clear that collaborative learning results in an additional stimulus that enhances learning straying from the traditional teacher and student interaction (see Reed, 2014; O'Brian et al., 2006). Despite this, there is an ongoing discussion around collaborative learning and group work and how to best implement in the classroom. Teachers and educators often assume that students especially in secondary education have already acquired the skills of effective collaboration. The justification is that primary pupils conduct many group tasks in lessons, thus, pupils should be able to recall these key skills in secondary education. Newer studies have found that this does not set any foundation for successful group work in later school (see Hoffman and Mercer, 2016). A study by Reed (2014) adds to the discussion, suggesting that groupings are critical to any group activity as different character traits allow many students to simply "coast by" with no real input into the session. Kagan (1994) had developed various structures that use heterogeneous groupings, equal participation and stimulus interaction as a successful guide to aid any group tasks. Johnson and Johnson (1999) say Kagan strategies are easy for pupils to learn and equal participation benefits the higher ability students as much as the lower ability students.

Group work integrates other pedagogical techniques such as differentiation and questioning. This can often rationalise the teacher performing group tasks regardless of its inappropriateness as pupils will still benefit from differentiation and scaffolding questions. The author conducted a practical session in a secondary Science lesson where pupils had to turn ice cubes into water vapour. Although lack of equipment meant group 
sizes were fives and sixes, each pupil had a differentiated task. For example, the lower ability pupils were timekeepers and in charge of a 'checklist', whereas the higher ability pupils were temperature monitors and recorded data for graphs. Although the group task itself was constrained, pupils were still benefitting from differentiation techniques.

Additionally, a 'mix, pair, share' Kagan strategy was adopted with the same group. In practice, the author found that pupils didn't have the skills to fully benefit from this task and collaborate effectively. Nelson and Johnson (1996) and Prater et al. (1998) have suggested limitations of Kagan include no pre-teaching of the skills required, although Johnson and Johnson (1999) indicate there is no need for this as the strategies are quick and easy to learn. Feedback is a form of assessment that is used to modify teaching and learning activities (see Black and Williams, 1998; Hramiak and Boulton, 2011). Feedback contributes key information for pupils relating to their goals, playing a decisive role in development. Traditionally, feedback has come from the teacher, either verbally or written. However more studies are now investigating the effectiveness of peer feedback. Gielen et al. (2010) examined the effectiveness of peer feedback vs teacher feedback; a total of 43 students were used across various writing assignments in English. The study reports that there was no significant difference in receiving feedback from a teacher or student, nevertheless students giving feedback did enhance their understanding of the topic.

Peer feedback is most effective across the Humanities where answers can be assessed on how well an argument is formed rather than which argument is constructed. Yet, during Sciences, there is much less scope for a correct answer, thus meaning peer feedback can become regressive if there are misconceptions (see Sweet and Michaelsen, 2010; Jigang, 2011). The author observed misconceptions whilst teaching a task where pupils had to peer assess their partner's description of photosynthesis. Some students were unaware of the difference between respiration and breathing. This led to full marks being awarded for pupils saying that plants breathe as oppose to respire. During an exam, marks would not have been awarded. In science, this misconception is common with pupils not fully understanding a physical process (breathing) compared to a chemical reaction (respiration); reflecting on this, pupils would've benefited from an AQA marks scheme to refer back to. However, this does highlight a drawback when using peer assessment.

Both pedagogy techniques are proven to enhance the teaching of a subject. Newer studies have investigated the effectiveness of providing feedback to groups. Previously, there has been a taboo around giving generalised feedback with the industry pushing personalised, individual feedback. Christopher (2016) examined work effort and work efficacy in groups and individuals aged 12-15 following teacher feedback. Results from an ANCOVA test revealed that groups receiving feedback work harder than individuals receiving the same feedback. Interestingly, individuals' work efficacy was greater than that of groups. It is unknown why groups tend to work harder to correct their mistakes but never quite meet the end goal like individuals do. Bandura (2006) dissects self-efficacy using the locus of control as a similar construct. Students in groups could quite possibility be aware that external forces (other members of the group) would determine whether outcomes are met; whereas students working as an individual knew that their outcome is determined by their self-efficacy. When discussing limitations, Christopher (2016) mentions the measure that was used for self-efficacy was unable to capture students' full perceived efficacy as the answers were set statements to choose from. The industry would heavily benefit from further research investigating self-efficacy of pupils in groups with designated roles. This 
project could potentially involve Kagan strategies to fully understand if roles that are given to certain pupils do in fact challenge and stretch learning. Kagan often comes under scrutiny for the lack of quantitative research (see Prater et al., 1998).

\section{Group Work: A DEeper Exploration}

There is a vast amount of literature on group work in classrooms and has been since the 1960s. However, there is still a significant need for research in this area due to a) the ever changing $21^{\text {st }}$ century and $b$ ) the amount of unanswered questions for teachers and practitioners, such as: How does an educator assign group tasks that encourage involvement, independence, a fair share of labour and in line with the curriculum? (See Johnson et al., 2014). As previously mentioned, researchers generally accept that group work is a high level skill for pupils to acquire. From experience, there seems to be a difference in the type of group work being used across subjects. For example, during an observation the author noticed the teacher encouraged socialising and group work without necessarily setting expectations. When observing specific group behaviour, it was clear most groups were 'on task' and practising their lines. At the end of the lesson, pupils perform their act in front of the whole class; this seemed to be enough for maintenance of successful collaborative work with pupils using low levels of anxiety positively to master rehearsing their lines. In Drama, loud, eccentric behaviour is accepted as a way to increase a pupil's confidence; when conducting Science experiments, there is a complete shift from socialising and a heavy emphasis on safety and sensible behaviour (expectations are briefed beforehand). The author found the session a more comprehensive way to work towards the lesson's learning objectives. This is due to the type of group work essentially being the assessment criteria. When compared to Science experiments, the assessment occurs post group work in the form of a report or test.

Reynolds (1994) identifies four different types of group work (role plays, action learning, discussion groups and experimental exercises) and summarizes the need for specific types in certain lessons. It is clear that when conducting Science experiments, there is a cross between action learning and experimental exercises. Reynolds (1994) suggests this is the most appropriate way for pupils to safely conduct a required practical. Drama lessons however, use role plays as it is an obvious way to understand and assess how pupils are coping in unfamiliar situations. A different approach to group work is that of Kagan (1989) who contributes that in cooperative learning the teacher designs the social interaction structures as well as learning activities. Slavin (1996) supports Kagan's approach as the critical element of working towards personal and team goals. By following Kagan's strategies, an educator is able to overcome the problem of the group shifting dependency to the most able member by giving specific roles (e.g. Person A is responsible for...... etc.).

The main theory that underpins group work and collaborative learning is often referred to as Social Constructivism. Constructivism is a broad term that has been grounded on research by Piaget and Vygotsky. One of main ideas from Social Constructivism is that social interactions are important to knowledge construction (see Bruning et al., 2004). Vygotsky asserted that the development of individuals, including their thoughts, languages, and reasoning processes, is a result of culture. These abilities are developed through social interactions with others; therefore, they represent the shared knowledge of a given culture (see Li and Lam, 2013). Vygotsky later studied the growth of children through interaction with others and concluded social environments contribute how children, learn, develop and grow. 
A well-known theory by Vygotsky is the 1920's ZPD. The ZPD proposes that each child has a development capacity; anything above this capacity is out of reach for a child to achieve. The difference between a child's actual development level and potential development level is called the ZPD. The potential development level is determined through a teacher's or adult's guidance. This implies that during more challenging tasks a child is able to learn from, collaboration with more able peers or adjusted support from the teacher. This theory has become important for researchers and educational psychologists as it gives teachers an active role in a child's development. A teacher is able to scaffold using correct analysis to allow children to challenge themselves without making the learning threatening (see MacGilchrist et al., 1997). Active teachers often criticize the ZPD for not taking into account a child's individual needs, instead engrossed on generalisation of all children. By ignoring individual needs, the ZPD fails to consider motivational influences of a child; making it far less accurate than first imagined (see Chaiklin, 2003). Lui and Matthews (2005) argue that the ZPD disregards the role of an individual but regards the collective. Upon deeper investigation, it does appear that the ZPD does not recognize the ability of individuals to rise above social norms based on personal understanding.

Contrastingly, Piaget (1896-1980) suggested cognitive development is related to age and isn't an active process as set out by Vygotsky. Piaget named four main stages: Sensory-motor period (0-2 years): movement and senses; Pre-operational period (2-7 years): language development; Concrete operation (7-11 years): conclusions drawn from observation; Formal operation: logical reasoning (see Hramiak \& Hudson, 2011). One of the main criticisms from this theory is the inattention of social and cultural backgrounds of pupils. It is unrealistic to think children develop cognitive abilities at the same in rate in the UK as in third world countries. Researchers such as Gray and Tall (1994) often link Piaget's theory to western schooling, pointing out that the formal operational period and even the concrete operational period are heavily dependent on formal Western schooling. Another major criticism of Piaget stems from the inaccuracy of the stages. Harris (1983) argues preoperational children are far less egocentric than Piaget originally believed. This may also suggest why some children actually never develop sound language skills. Other researchers such as Weiten (1992) add to this by stating some children never achieve the formal operations stage, continuing to struggle with rationale thinking until adulthood.

The author's experience in teaching differs significantly to Piaget's four main stages. During a primary education visit examining, the author found that even the youngest pupils (age 5) were able to mimic the teacher from observation. Piaget's theory states this does happen until later in life (7-11 years), thus, bringing the four stages into disrepute. Lourenco and Machado (1996) defend the four stages by suggesting some interpretations of ages are incorrect. They go on to say "the difference between chronological ages and operational ages is straight forward". Although the concrete operation stage is set between 7-11 years, most children will advance earlier than this. Thus, a child will have a greater operational age than chronological.

\section{CONCLUSION}

Group work in general, can elevate the learnings of students past the superficial and into deeper learning that remains for life (see Marzano, 2003; Reed, 2014). It is clear group work has become a focal point in classrooms across the U.K. Most applications have come from international research such as Kagan (1994) and Vygotsky. However newer research, specifically looking at the curriculum and classrooms in the U.K is now being conducted (see 
Murphy et al., 2015; O'Sullivan and Seabra, 2016). Teaching practice so far has shown the author that group work can go beyond a group discussion or science experiment; this is supported by Reynolds (1994) who picked out four different types of group work. Reynolds (1994) continues by confirming action learning and experimental exercises are best for a required practical in Science. Having observed lessons in different subjects, it became apparent group work in subjects like Drama directly link to the assessment of that pupil. This is compared to Science where assessment occurs after the group activity. Kagan structures have become very popular in mainstream education over the last 5 years. Upon evaluating Kagan strategies, it was discovered that there was a need for pre-teaching of the strategies for pupils. Other researchers support this claim; Nelson and Johnson (1996) and Prater et al. (1998) are often critical of Kagan strategies, suggesting there is no pre teaching of the skills and no quantitative research to verify the effectiveness for educators.

Vygotsky's 1920's ZPD is a well-respected theory used across the education industry. In relation to group work, the theory suggests pupils can reach their potential learning capacity through successful collaboration and peer support. Vygosksy takes a social constructivism approach, meaning that pupils' learning capacity is dependent on social and cultural upbringing. Modern day teachers have become sceptical of the ZPD, highlighting deficiencies in personalised needs of pupils (see Chaiklin, 2003).

Through investigating group work as a pedagogical technique, the author was able to use key literature to support and enhance teaching practice. Initial thinking had been that, group work was a complex activity to carry out with very little, if any self-efficacy benefit to the pupils. As a newly qualified educator, group work increases the chance of having to deal with poor behaviour. It is apparent that the author's thinking had evolved; now knowing, during group work a practitioner is able to differentiate, scaffold, question and give feedback. In addition to behaviour being easily managed by careful groupings before the activity. The author has also been actively using Kagan strategies in the classroom as part of starter and plenary tasks. Over continuous practice for 3 months, pupils are now comfortably aware of what is expected of them; this has really improved full participation and the quality of answers that are produced.

Future research must consider group work and the use of $21^{\text {st }}$ century technologies. There has been very little evidence to make arguments for or against the use of iPads and mobile devices in the classroom as part of a group activity (see Ferguson, 2015). By piloting research in this area, teachers will know if pupils can collaborate as effectively via online platforms or even in different rooms with the use of technology. There is also a need for research on the self-efficacy benefit to pupils where there are designed roles in group work. Komarraju and Nadler (2013) recommend future research must look at the implications of certain roles in groups in relation to cognitive development. There is a worry that specific group roles can cap pupils learning

As a closing remark, group work is one of the most studied pedagogical techniques in the industry. Teachers across primary and secondary education are seeing the benefit of group work in their classrooms. Piaget and Vygotsky's theories are well respected and have been the base for decades of research. However, many teachers have now become sceptical of them and struggle to see the relevance in $21^{\text {st }}$ century classrooms. There is now an opportunity to conduct research on self-efficacy of pupils in groups and how modern day technologies can be integrated into group learning. 


\section{REFERENCES}

Bandura, A. (2006). Guide for constructing self-efficacy scales, In F. Pajares \& T. Urdan (Eds.), Self-efficacy beliefs of adolescents, pp. 307-337 Connecticut: Information Age.

Black, P., \& William, D. (1998). Assessment and Classroom Learning. Assessment in Education, 5(1), 7-74.

Brown, S., Kirkpatrick, M., Mangum, M., Avery, J (2009). A Review of Narrative Pedagogy Strategies to Transform Traditional Nursing Education. Journal of Nursing Education, 47(6), 283-286.

Bruning, R., Schraw, J., Norby, M., and Ronning, R. (2004). Cognitive Psychology and Instruction (4 $4^{\text {th }}$ ed.) Columbus, $\mathrm{OH}$ : Merrill.

Chaiklin, S. (2003). The zone of proximal development in Vygotsky's theory of learning and school instruction.

Christopher, J. (2016). Group feedback in the classroom promotes home energy conservation. College of Natural Resources, 5, 4-88.

Costa, P., Terracciano, A., McCrae, R. (2001). Gender differences in personality traits across cultures: robust and surprising findings. Journal of Personality and Social Psychology, 81(2), 322-331.

Ellsworth, E. (1989a). Why Doesn't This Feel Empowering? Working Through the Repressive Myths of Critical Pedagogy. Harvard Educational Review 59(3) pp. 297-325.

Ellsworth, E. (1989b). Teaching Positions: Difference, Pedagogy, and the Power of Address. New York: Teachers College Press.

Feingold, A. (1993). Cognitive gender differences: A developmental perspective. Sex Roles: A Journal of Research, 29(1-2), 91-112.

Ferguson, C. (2013). It's time for the nursing profession to leverage social media. Journal of Advanced Nursing, 69, 745-747.

Gielen, S., Tops, L., Dochy, F., Onghena, P., Smeets, S. (2010). A comparative study of peer and teacher feedback and of various peer feedback forms in a secondary school writing curriculum. British Educational Research Journal, 36(1), 143-162.

Giroux, H. (2017). Pedagogy, Civil Rights, and the Project of Insurrectional Democracy. Howard Journal of Communications, 28(2), 203-206.

Giroux, H., \& Shannon, P. (2013). Education and Cultural Studies: Towards a Performative Practice. London: Routledge.

Gray, E., Tall, D. (1994). Duality, ambiguity, and flexibility: a 'proceptual' view of simple Arithmetic. Edu, 25(2), 116-140.

Harris, P. (1983) Infant cognition: Handbook of child psychology: Infancy and developmental psychobiology (2) New York: Wiley.

Hoffman, R., \& Mercer, N. (2016). Teacher interventions in small group work in secondary mathematics and science lessons. Language and Education, 30(5), 400-416.

Hramiak, A., \& Boutlon, H. (2011). Exploring student and tutor perceptions of feedback in Post Graduate study. Society for Research in Higher Education, 1-3.

Hramiak, A., \& Hudson, T. (Eds), (2011). Understanding Learning \& Teaching in Secondary Schools. Harlow: Pearson Education Limited.

Jigang, C. (2011). A contrastive study of online peer feedback and online teacher feedback on Chinese college students' English writing. The Chinese Journal, 2, pp.319.

Johnson, D., Johnson, R., Smith, K. (2014). Cooperative learning: Improving university instruction by basing practice on validated theory. Journal on Excellence in College Teaching, 25(3\&4), 85-118.

Johnson, W., Johnson, T. (1999). Learning Together and Alone: Cooperative, Competitive, and Individualistic Learning (5th ed.). Boston: Allyn and Bacon. 
Kagan, S. (1989). The structural approach to cooperative learning. Educational Leadership, 12, 12-15.

Kagan, S. (1994). Cooperative Learning. California: Kagan Publishing.

Komarraju, M., \& Nadler, D (2013). Self-efficacy and academic achievement: Why do implicit beliefs, goals, and effort regulation matter? Learning and Individual Differences, 25, 67-72

Ladwig, J., Smith, M., Gore. J., Amosa, W., Griffiths, T. (2007). Quality of pedagogy and student achievement: multi-level replication of authentic pedagogy. Australian Association for Research in Education, 1-15.

Li, M., \& Lam, B. (2013). Cooperative Learning. The Hong Kong Institute of Education, pp.1-33.

Lourenço, O., \& Machado, A. (1996). In defense of Piaget's theory: A reply to 10 common criticisms. Psychological Review, 103(1), 143-164. https:/ / doi.org/10.1037/0033-295X.103.1.143

Lui, C. H., \& Matthews, R. (2005). 'Vygotsky's philosophy: Constructivism and its criticisms examined. International Educational Journal, 6(3), 386-399.

Lusted, D. (1986). Why Pedagogy? Screen, 27(5), 2-16.

MacGilchrist, B., Myers, K., Reed, J. (1997). The Intelligent School. London: Paul Chapman Publishing

Marzano, J. (2003). What works in schools. Alexandria. VA: ASCD.

Murphy, C., Scantlebury, K., Milne, C. (2015). Using Vygotsky's zone of proximal development to propose and test an explanatory model for conceptualising co-teaching in pre-service science teacher education. Asia-Pacific Journal of Teacher Education, 43(4), 281-295.

Myers, L., Faunce, E., Doutt, K., Dunbar, D., Parsons, J., Moy, E., Sheety, A. (2016). University Partnerships for Academic Program and Professional Development: Building Faculty Capacity for 21st Century Teaching and Learning. Emerald Group Publishing Limited, 221 - 241.

Nelson, R., Johnson, A. (1996). Effects of direct instruction, cooperative learning, and independent learning practices on the classroom behaviour of students with behavioural disorders: A comparative analysis. Journal of Emotional \& Behavioural Disorders, 4, 53-63.

O'Brian, M., Munro, S., Payton, J (2006). Common Ground: Teaching Kids the Benefits of Working Together. Edutopia, 10(1).

O'Sullivan, L., Seabra, N. (2006). School in a Box in Low Resource Primary School in Mozambique: Practical Application of Zone of Proximal Development in Teacher Training with Mobile Technology. International Journal of Mobile and Blended Learning, 8(2), 1-13.

Pomerantz, E., Alterman, E., Saxon, J. (2002). Girls and boys experience academic difficulties very differently. Journal of Educational Psychology, 94(2), 396-404.

Prater, A., Bruhl, S., Serna, A. (1998). Acquiring social skills through cooperative learning and teacherdirected instruction. Remedial and Special Education, 19, 160-172.

Reed, Z. (2014). Collaborative Learning in the Classroom. Center for Faculty Excellence, 1-6.

Reynolds, M. (1994). Group Work in Education and Training. London: Routledge.

Slavin, R. E. (1996). Research on cooperative learning and achievement: What we know. Contemporary Educational Psychology, 21(1), 43-69.

Sweet, M., Michaelson, L. (2010). Team based learning in the Social Sciences and Humanities. Virginia: Stylus Publishing.

Weiten, W. (1992) Psychology: themes and variations (2nd edn). California: Brooks/Cole Publishing Company. 